\title{
ESTRATEGIAS PATRIMONIALES EXCLUYENTES. UN CASO FRANCÉS.
}

por

\author{
ROSE DUROUX \\ Universidad de Clermont-Ferrand
}

RESUMEN: Auvermia es una región de transmisión integral de la propiedad, es decir una tierra de familias troncales. Mi intención es mostrar cómo influye la emigración a España de los babitantes de alta Auvernia (departamento del Cantal) en la transmisión del patrimonio. En esta sociedad de familias troncales ccuál es el destino reservado a los aexcluidos" de la sucesion? La emigración de que se trata es masculina, rural, colectiva, plurianual y alternativa: los emigrantes se van por tumo de dos o tres años $y$ vuelven a la finca a pasar un año aproximadamente. Este vaivén suscita redistribuciones cíclicas de poderes en cada familia. Nos damos cuenta de que unas de las respuestas dadas a la inestabilidad es instituir aberederan a una de las bijas. En esta zona migratoria peculiar son las mujeres las que aportan la tiesra: la tasa de berederas puede alcanzar el 60\%, tasa sorprendente en la Francia rural donde sólo zonas vascas alcanzan tales proporciones. El segundón emigrante y célibe es el excluido por antonomasia.

PaLAbras Clave: Francia rural. Familia troncal. Emigración. Prácticas sucesorias. Herederos. Excluido.

ABSTRACT: Auvergne was a stem-family country where property was passed on in its entirety. My purpose is to show bow the emigration towards Spain of the people from Haute Auvergne (the region called Cantal) influenced, until the twentieth century, the unequal sharing-out of the patrimony. In that stem-family society, what fate was in store for those excluded from the inberitance of family property? The kind of emigration we are concemed with is a rural one, carried out in groups several times year on a rota basis, that is to say the migrants went to Spain in rotation for two or three years and came back to their farms for about a year. These to-ings and froings entailed cyclic redistributions of responsibility in the family. These people realized that one of the answers to this unstable pattern was to make one of the daugbters the beiress. In this precise centre of emigration, the women brought the

Hispania, LX/1, núm. 204 (2000) 315-330 
land: the rate can reach $60 \%$ of the cases; such a rate is very uncommon in ruval France and can be found only in the Basque country. The youngest sons, if they emigrated and were moreover bacbelors, were the deprived of that period.

KEY WORDS: Rural France. Stem-family. Inheritance system. Heir. Excluded.

Para entender la lógica de los mecanismos sociales y jurídicos de una sociedad rural como la sociedad cantalesa del siglo XIX, caracterizada por la práctica de una emigración tradicional hacia España, es conveniente hacer mención del panorama geográfico e histórico en el que se desenvuelve. Simplificando podemos decir que las tierras altas de Auvernia, situadas al oeste del Macizo Central, conforman una región ganadera de "media montaña» en donde los campesinos serán mayoritariamente propietarios y explotarán directamente sus tierras. En esta zona, que engloba algunos pueblos de la Xaintrie lemosina, se practican, con la intención de mejorar el nivel de vida o de enriquecerse, varios tipos de migraciones, internas o externas, temporales o estacionales, que parecen dirigirse particularmente hacia Aquitania y España, al menos hasta el inicio del éxodo masivo hacia París. De hecho, y hasta ese éxodo, la emigración a España había supuesto para esta zona su mejor recurso socio-económico. En esta tesitura, cabría entonces preguntarse qué tipo de emigración se afronta.

Desde el siglo XV, los cantaleses han ejercido toda clase de oficios en el territorio español, antes de seleccionar, en el siglo XIX, tres ámbitos profesionales bien diferenciados : el ejercicio de la panadería en Madrid, la venta polivalente en los pueblos de Castilla y la trata de ganado equino en Levante. Estos comerciantes, panaderos, tenderos o tratantes formatán en España compañías mercantiles cuyas dimensiones son variables. El funcionamiento de dichas compañías es como sigue: tras siete años de aprendizaje -en principio- cada socio participará progresivamente en el reparto de beneficios (dieciséis escalones de un año u ocho de dos). Las salidas a España son realizadas por turno, y duran entre dos y tres años, alternadas con descansos de larga duración que pueden alcanzat un año. Bien llevada, una carrera de este tipo se termina a los cuarenta y tantos años de edad, aunque no siempre es así.

Forzosamente, esta migración plurianual provocará desórdenes y tensiones en todos los niveles de la pirámide familiar, al suscitar en ella compromisos y redistribuciones cíclicas de espacios y de funciones entre sus componentes (ya sean poderes centrales, subsecuentes o adyacentes). Mi intención es la comprensión de los engranajes concretos y simbólicos de este modus vivendi tradicional: observaré el modo de vida con la perspectiva de la exclusión que ha

" Duroux, Rose: Les Auvergnats de Castille. Renaissance et mort dune migration au XIXe siècle, Prólogo de Bernard Vincent, Clermont-Ferrand, Association des Publications de la Faculté des Lettres, 1992, $2^{2}$ ed. 1995.

Hippania, LX/1, núm. 204 (2000) $315-330$ 
podido originar una migración por turno. Manejaré en paralelo o de manera cruzada las nociones de exclusión e inclusión, puesto que la única forma de comprender al «excluido» de la sucesión hereditaria es aislando al «elegido». Además, no se pueden observar las consecuencias de la ausencia sin sondear de antemano el terreno que la ha provocado, es decir, tanto el dispositivo patrimonial como el régimen sucesorio establecido. Por fin, mi intención no es la de interesarme tan sólo en la exclusión hereditaria sino también en la familiar, parroquial, nacional, cultural..., en una palabra, en la exclusión plural: ese mosaico de exclusiones nacidas de la puesta en práctica de una serie de estrategias existenciales que ha venido suministrando generaciones de emigrantes conocidos popularmente como los Espagnols ${ }^{2}$.

\section{PRÁCtICAS MATRIMONIALES Y SUCESORIAS}

La tradición local antes y después de la instauración del Código civil de 1804

Sabemos que cada sociedad campesina genera un modo de transmisión del patrimonio, por lo que cabe preguntarse qué estructura presenta en la época contemporánea el núcleo social en tierra de las grandes migraciones.

Digamos de entrada que el «modelo» dominante es el de la familia troncal con un solo heredero. Su finalidad es evidente: evitar la dispersión del patrimonio y del linaje. Así la Alta Auvernia obedecía, desde el punto de vista sucesorio, al principio meridional de la transmisión desigual de bienes, el cual consiste en dar prioridad al primogénito en perjuicio de sus hermanos y hermanas. Pero este principio se fue modificando, y de este modo: el derecho de primogenitura fue reemplazado por una elección arbitraria, por lo que el acto mismo de elegir un heredero se conoce como «hacer al primogénito», incluso si el elegido es el hijo menor ${ }^{3}$.

2 DUROUX, Rose: «Destins d'exclus. De la France vers l'Espagne. XIX siècle. Reconstitutions familiales", in Transmission de la terre en Europe et en Amerique (XVIle-XXe siètles). Effets saciaux d'un processus économique, dir. Joseph Goy et Gérard Bouchard, XII ${ }^{D}$ Congreso Incernacional de Historia Económica, Madrid, 24-28 agosto, 1998, Preactas.

3 A propósito del régimen sucesorio, Léonce Bouyssou, archivera, me confirma — después de repasar las notas para su tesis de la "École des Chartes» procedentes del examen de un gran número de archivos (unos 150 registros nocariales) - que, si bien menos estable que en épocas más recientes, ya en el siglo XV se desprende, en medio de cierta diversidad, la idea clave de evitar la parcelación del patrimonio, ya sea por la institución de un heredero universal, a veces de dos (generalmente el primogénito y el ultimogéniro), ya sea por la constitución de comunidades familiares (regidas por convenciones precisas). Esta última solución tenderá a desaparecer poco a poco ya que se produce la separación de los bienes en caso de separación de los miembros. Con respecto a la emigración se puede apreciar que eran sobre todo los solteros los que se iban, sea a países lejanos, sin más precisión («ad partes extraneas, longinquas et remotas"), sea a España (en cuyo caso algunos hacían donación 
El padre o la madre transmiten lo esencial de los bienes a un solo hijo, quien quedará encargado de dotar en dinero a sus hermanos y hermanas. En teoría, esta forma de compensación está fundada en la estimación aproximada de la parte natural de cada uno en la herencia. En la práctica, los hermanos y las hermanas se contentarán con una legítima en metálico cuyo montante no tiene relación alguna con la estimación del valor monetatio del dividendo unitario, y así se evita el riesgo de una partición del patrimonio, lo que se trata de evitar a cualquier precio. El sistema no obstante tiene muchos fallos : "Por un lado, la ausencia de descendientes directos o la incuria imprevista de un heredero bien pueden acarrear una transferencia masiva o una destrucción lenta del patrimonio. Por otro lado, bajo la presión de los hijos menores desfavorecidos, se producen de vez en cuando desmembramientos parciales de la herencia principal que escapan a esta regla general. La indemnización de los excluidos aunque sea insignificante, el pago de la legítima o la atribución de la dote, llegan a provocar choques, incluso en momentos de prosperidad. Y por eso, cuando no es posible aplazar por más tiempo el pago de la cantidad debida, no queda más remedio que ceder una o varias parcelas para resarcir a los coherederos o a los acreedores" ${ }^{4}$. Esta transmisión de bienes no se hacía en Auvernia por vía testamentaria, sino más bien a título de partición de bienes anticipada. Es decir, la operación solía verificarse con motivo del primer enlace matrimonial (indiferentemente de que se tratase del matrimonio del hijo mayor o del hijo menor, del heredero/heredera o de uno de sus hermanos). En matrimonios posteriores se afinaban las cláusulas que los testamentos no hacían más que confirmar, por lo que la elección del heredero asumía entonces carácter oficial, aunque era frecuente que el padre (o la madre) se reservase el usufructo de los bienes como una garantía para su vejez. Como es natural, los herederos no debían casarse entre sí, pues los excluidos esperaban entrar como yernos en otras familias troncales contrayendo matrimonio, a ser posible, con una heredera. No todos lo conseguían... Los eternos segundones, si son capaces de ello, irán a buscar fortuna a otra parte. En mi opinión, no cabe duda de que exclusión y emigración han sido programadas frecuentemente desde su infancias.

\footnotetext{
de sus bienes a los hermanos o parientes "casu quo moriatur in patria Spanhae"); pero también se iban algunos hombres casados, como Pierre Auzolles, de Vic, el cual dio todos sus bienes a su mujer antes de emprender el viaje. Léonce Bouyssou encontró igualmenze un formulario notarial donde rezaba: "Venditio facta per uxorem, absente marito, pro alimentando se et liberos...». La emigración de parejas - -sin hijos desde luego- parece excepcional. Una de ellas, Jean de Vemh de Arpajon y su mujer Marguerite, residentes en Toledo, vende a Jacques Malroux, vecino de Aurillac, los bienes que habían confiado al marcharse a España a su vecino Marrin Troupel.

4 Intervención de Gérard Béaur en el XI Congreso de Milano, AIHE, C33, org. GoY, J., BOUCHARD, G., 1994, Preactas, "La transmission des exploitarions: logiques et stratégies». Ed. École Française de Rome, 1998. En lo que concieme Auvernia, el "sistema de casa" que estudia Elisabeth Traissac — «Une proptiété rutale de Haute-Auvergne au XVIIle siècle», Revue de la Haute-Anvergne, julio-septiembre 1967, julio-septiembre 1968- ilustra perfectamente los propósitos de Gérard Béaur.

5 La exclusión puede hacerse desde la infancia: «las familias toncales colocan a veces a los hijos como domésticos en otras familias, pero sin verdadera reciprocidad: la colocación responde
} 
Este modo de transmisión sobrevivió al Código civil de 1804 . Pero, en el curso del siglo XIX, y aún más en el del XX, el contrato de matrimonio tenderá a ser sustituido por lo que se ha dado en llamar en Auvernia y en la limitrofe Xaintrie : «l'arrangement» - el arreglo. «Faire l'arrangement», equivale a autentificar ante un notario la elección oficiosa del heredero. En 1928, Madeleine Basserre, en su tesis sobre la geografía del Cantal, afirmaba que hasta esa fecha no se habían producido cambios sustanciales en este proceder: «Se trata de dar al heredero, a título de mejora y fuera del reparto, el cuarto de todos los bienes; luego, por un acto notarial subsecuente, los hijos legan sus derechos al heredero, quedando a cargo de éste el alimentar, cuidar y mantener a los padres ancianos, y abonar a sus hermanos una cierta cantidad pagable a largo plazon' ${ }^{6}$. Basta con infravalorar los bienes hasta el extremo y así se dará a esta operación la apariencia de una partición legal. El arreglo es pues una especie de entronización del heredero, la cual se hace en el momento que los ancianos crean más conveniente ; éstos, a veces, con el objetivo de tener controlados a todos los miembros de la casa, retrasarán su oficialización lo más posible.

\section{Balances y juicios contemporáneos}

Escuchemos a un auvernés indignado, M. Odoul -tal vez un segundón expoliado-, para quien la transmisión desigualitaria es absolutamente reprobable porque supone una negación de la justicia y un perjuicio para la economía local, ya que, al apartar de la sucesión a los herederos los impulsa a la emigración y, por ende, al abandono del campo. En 1840, este autor capta de forma incisiva las tensiones de su tiempo, razón por la cual le cedemos ampliamente la palabra:

«Esta costumbre absurda y desleal es practicada en nuestra región casi con tanto cinismo como tiempo atrás; como la legislación moderna se opone a la transmisión directa de todos los bienes en provecho de un solo hijo, se recurre a cualquier medio, a astutos subterfugios; así se le da al hijo mayor educación universitaria, se le ofrecen estudios superiores, se le procura un instrumento de trabajo de gran valor al facilitarle una profesión liberal, mientras que los otros hijos se quedan en el mezquino ámbito de los trabajos manuales y de la instrucción primaria. Se aumentan, además, las ventajas del que llamamos jefe troncal, del heredero del patrimonio, con los capitales que se transmiten de mano a mano, por testamentos a su favor impuestos a tías y a tíos, por donaciones disimuladas, y mediante cualquier otro ardid posible. Estos fraudes mi-

aquí mucho menos a la preocupación de completar el aprendizaje de los hijos que a la de apartarlos de la sucesión", Histoire de la Famille, dir. André Burguière, Christiane Klapisch-Zuber, Marcine Ségalen, Françoise Zonabend, París, Armand Colin, 1986, t. 2, p. 49.

6 DURAND, Alfred: La vie rurale dans les massiffs volcaniques des Dores, du Cézallier, du Cantal et de l'Aubrac, Aurillac, USHA, 1946, p. 149. 
serables están tan enraizados en las costumbres que la opinión pública no los reprueba en absoluto, y hasta el mismo clero es cómplice de todas estas barbaridades, al menos por su silencio.

Se aceptan todos estos actos, todas estas expoliaciones; primeto se le deja al hijo mayor disfrutar del privilegio de la educación y luego, además, se le deja disfrutar a él solo del beneficio de los bienes durante la vida del padre, mientras que los otros hijos no tienen derecho ni al capital ni a las ganancias hasta la muerte del padre. Han de esperar a que su tumba esté cerrada para reclamar una parte, siempre mínima, de la herencia común. Entonces surgen los pleitos y las consabidas demoras, casi siempre calculadas, de una partición judicial. El hijo mayor, que es el único poseedor, especula con las necesidades de sus hermanos y de sus pobres hermanas, los cansa, fatiga su paciencia con incidentes en el procedimiento judicial, con obstáculos de todo tipo, con el fin de comprarles por debajo de su valor, a menudo a muy bajo precio, su cuota patrimonial, su parte hereditaria.

Así, durante la primera fase, al menos la mitad de la vida de cada generación, la propiedad se encuentra en manos de quien retiene todos los ingresos, la agota para hacer que rinda todo lo que pueda producir y además tiene interés en degradarla para que, llegado el día de la repartición, la estimación sea lo más baja posible y así poder retenerla o recuperarla con los mínimos gastos (...). Estas son las causas principales de esta emigración que se perpetúa como una calamidad; las otras causas son sólo accidentales y secundarias" ${ }^{7}$.

¿Se trata en este caso que nos presenta Odoul de una exclusión extrema en la que el heredero se beneficia a la vez de la tierra y de la educación, acumulando el capital cultural e hipotecario? ¿Es corriente un acaparamiento tan exclusivo a mediados del siglo XIX? No podría decirlo. Veamos, ahora, el punto de vista de Madeleine Basserre expresado en el período de entreguerras: "Cuando el padre es inteligente, deja la totalidad de los bienes al hijo mayor, dándole al hijo menor una instrucción más desarrollada, impulsándole a la magistratura; en el Cantal se ven ejemplos frecuentes de dos hermanos de los que uno se quedó sin educación, como campesino cuidando de sus animales y de su campo, mientras que el otro, distinguido abogado, abandonó su tierra natal para ir a Clermont o París"s.

¿Cómo se elige al futuro magistrado o médico? ¿Se trata de una lotería sin más? ¿Una lotería en la que el desfavorecido es el «destripaterrones» heredero? El tono con el que estos dos observadores enuncian los calificativos «manual», "primario» y "grosero" no deja lugar a dudas. En 1928, cuando M. Basserre lleva a cabo su encuesta, el acceso a la universidad sigue siendo un privilegio supremo a pesar de la generalización de la enseñanza primaria. Sin embargo

7 ODOul: «De l'émigration», Revue d'Auvergne, 1840, p. 72-75.

8 BASSERre, M.: Le Cantal, economie agricole et pastorale, Thèse, Auriltac, Imprimerie Moderne, 1928 , p. 139.

Hispania, LX/1, núm. 204 (2000) 315-330 
una cosa ha cambiado: la presión demográfica ha comenzado a ceder: caída de la natalidad, éxodo rural, Primera Guerra Mundial... Quizás por esta razón la lotería sucesoria es presentada ahora con tonos menos repulsivos. Uno de los límites de la documentación anterior es que reduce la muestra a dos casos, el beneficiado de los estudios y/o el de la tierra, y deja en silencio al "excluido profundo", a aquel que no tendrá ni la tierra ni la profesión liberal, y que, si no va a buscar el «dinero de la emigración», se verá amenazado con el descenso social?.

Justificado o injustificado, el «sistema" perdura: "La familia troncal resiste aún en el siglo XX porque corresponde a un modo de explotación agrícola de pequeñas propiedades familiares, que la ausencia de partición entre los hijos permite salvaguardar unas generaciones más» ${ }^{10}$. Que toda una sociedad haya preservado un modelo ancestral de transmisión de bienes, más allá de la ley y de la equidad, prueba el valor que ésta le atribuye.

\section{LAS COMBINACIONES DOMESTICAS DE EXCLUSIÓN}

\section{Reproducción social. Estructura y coyuntura}

¿Qué observamos en el interior de esta estructura regional, de apariencia inmutable, al penetrar en las casas de los emigrantes? En principio todo es globalmente estable, peto rápidamente nos damos cuenta de que los microcosmos domésticos son muy móviles: una designación de heredero o una decisión matrimonial provocan combinaciones coyunturales - transversales y horizontales- que se suceden en cadena. Las defensas contra las disfunciones difieren de una casa a otra, de una generación a otra: selección, dosificación de las legítimas, instrucción, emigración, soltería, retraso o adelanto del matrimonio del heredero/a para alargar $o$ acelerar el recambio generacional, esterilidad calculada... En definitiva, lo que encontramos aquí son los clásicos medios de reproducción del «modelo» dominante, vigentes en muchas tierras altas de Europa. Pierre Bourdieu no decía otra cosa en Estrategias matrimoniales: «Las estrategias propiamente matrimoniales no se pueden disociar, sin abstracciones, de las estrategias sucesorias, ni tampoco de las estrategias de fecundidad, ni siquiera de las estrategias pedagógicas, es decir, del conjunto de estrategias de reproducción biológica, cultural y social que todo grupo pone en marcha para

\footnotetext{
9 Las disparidades entre hermanos son notables. Citaré el caso de la familia Saliège de Moussages (Cantal). El padre es panadero en Madrid, dos hijos son traperos en el Rastro de Madrid, el tercero es el cardenal Saliège (1870-1956). Adivinamos las mismas disparidades en la "Casa de Nicquesm -una de tantas: véase Duroux, R: Les Atwergnats de Castille, op. cit., anexo 11, p. 452-453. 10 BASSERre, M.: op. cit., p. 139.
} 
transmitir a la generación siguiente, mantenidos o aumentados, los poderes que él mismo ha heredado ${ }^{11}$.

\section{La co-residencia}

Sabemos que el sistema de transmisión indivisible implica a menudo la coresidencia de dos parejas «dinásticas»: la donadora y la donataria. Hace tiempo que las mismas disposiciones han sido observadas en otras casas europeas de familias montañesas: tres generaciones conviven durante algunos años, el padre y/o la madre con la pareja donataria y sus hijos, junto a los hermanos y hermanas solteros del heredero; también es corriente encontrar al hermano (o hermana) del jefe de familia: un soltero que se ha quedado in situ como doméstico. El contrato secular comportaba en Auvernia, como en otros lugares, una cláusula de incompatibilidad bajo el mismo techo, que funciona en caso de que la pareja heredera no se llevara bien con los donadores. En realidad se trata de una especie de asignación de pensión en especie o en metálico en beneficio de los padres si son excluidos de la vivienda. No obstante, en el caso de migrantes plurianuales, los solteros - tío y tía, hermanos y hermanas-son más numerosos que en otras partes, al parecer, para compensar las largas y repetidas ausencias, y a menudo no hay más criados que ellos ${ }^{12}$. En el caso de estos hermanos podríamos hablar de exclusión en grado superior. Contrariamente a lo que sugiere su etimología, vemos a la larga que la familia troncal es cambiante e inestable. El entramado doméstico pasa cíclicamente, como si de un acordeón se tratara, de una estructura amplia a un núcleo reducido. Cada fase de ese ciclo dará origen a incertidumbres y crisis, a desigualdades y selecciones, a exclusiones e inclusiones. Se intuye pues la arbitrariedad que preside la elección del «mayor». Todo sugiere que su designación suscitará rivalidades entre los hijos, tensiones entre los padres con su prole mientras el heredero no haya sido designado, crispaciones entre el jefe de familia y el elegido, quien estará impaciente por disponer de los plenos poderes. Pero, a fin de cuentas, lo que más llama la atención de este sistema es la plasticidad del conjunto, el amortiguamiento frecuente de choques, la facultad del grupo doméstico para tapar las brechas.

Bajo la óptica desigual del linaje, y pese a todos los a priori, la emigración será mucho más un factor de estabilización que de inestabilidad, pues será una solución a las inflaciones y contracciones de la familia troncal, permitiendo, según la coyuntura, achicar la embarcación o, a la inversa, ponerla a flote. Y Alfred Durand comenta: «Podemos ver, según la opinión de los notarios del

$"$ Annales ESC, $n^{\circ} 4-5,1972$, p. 1124 y Choses dites, París, Ed. Minuit, 1987, p. 85. Véase también FAJve-CHAMOUX, Antoinette: «Le fonctionnemens de la famille-souche dans les Baronnies des Pyrénées avant 1914\%, Annales $D H, 1987$, p. 241.

12 TRAissac, E.: op. cit. 
Cantal, casos sorprendentes de desprendimienton ${ }^{13}$, y hay motivos para asombrarse de la sorpresa de los notarios, pues ellos son esos grandes canalizadores de la operación, los primeros inspiradores de los «arreglos».

El hecho es que, como antiguamente, los excluidos tampoco reclamarán en el siglo XX su justa parte de herencia de manera violenta. Bien es verdad que la presión demográfica es menor y que la instrucción está mejor repartida. Pero no es aventurado afirmar que si el sistema resiste hasta el siglo XX, es porque los excluidos - con algunas excepciones - se auto-excluyen, impregnados de un principio de legitimidad en el que subyace una desigualdad ineludible. Y eso que, para aceptar el privilegio, los excluidos de Auvernia ni siquiera tienen el argumento de la fatal prioridad de edad de la primogenitura como sí lo tienen los segundones del sur de Francia, en donde, como advierte Yves Castan, «la ley del reparto desigual de los bienes pesaba en las mentalidades, cualquiera que fuera la larga costumbre de esta práctican ${ }^{14}$. Pronto se descubre que los excluidos seguirán indecisos entre sus asignaciones por un lado, y sus pretensiones a la herencia por otro: las recriminaciones salen a la luz cuando la legítima tarda en llegar (icinco años, quince, una generación...! y en pequeñas cantidades), pero suelen ser en buena lid. No obstante, sería interesante tener las estadísticas de los "disconformes" con la exclusión, incluso a través de un prisma tan deformante como los archivos judiciales. En este sentido, E. Traissac presenta un estudio ejemplar de la confusión existente en las legítimas, nunca suficientemente aclarada, que salta por encima de las generaciones. Advierte que los solteros que se quedan en casa resultan pésimamente indemnizados, y eso cuando se les indemniza.

¿Qué habrían podido hacer los hijos disconformes en una sociedad rural estructurada de esta manera? Nada. La exclusión, llevada a semejante grado, cabe repetirlo, supone que todo se desarrolla en un ambiente altamente consensual. En caso de litigio, siempre le queda al padre $\longrightarrow$ a la madre, da igual--, el recurso de reconocerse como deudor del hijo que se queda en casa; entonces puede verse obligado a cederle, dentro de la legalidad, una buena parte de sus bienes...

\section{REAJUSTES SOCIALES INDUCIDOS POR LA EMIGRACIÓN}

\section{Grados de exclusión}

Los que no siguen el juego - los que no se adhieren a las representaciones dominantes - quedan fuera de él, y el cuerpo social se las arreglará para ex-

13 DuRAnd, A.: $o p$. cit., p. 149.

14 CASTAN, Yves: «Arbitraire du droit à tester et révolte des fils en Languedoc au XVIIIe sièclen, Le modele familial européen, École Française de Rome, París, Ed. De Boccard, I986, p. 174.

Hispania, LX/1, núm. 204 (2000) 315-330 
cluirlos. La emigración sirve de cómodo remedio a muchos males; otras veces el «mal número» en el sorteo militar llega oportunamente. Pero la descalificación no se acompaña necesariamente del alejamiento físico, puede ser un descrédito, es decir una exclusión por desprestigio.

En cada generación, la mayoría de los que fueron educados en este código social se acostumbran a la idea de desarraigarse: colocarse en otra granja, casarse mal que bien en la vecindad, hacerse religioso, emigrar a España o a París..., a menos que se tenga la vocación y la ocasión de quedarse bajo el techo familiar con el estatuto poco lucido de "soltero doméstico". El heredero o la heredera serán así ayudados "por un tío que, ex-mozo emigrante, ha traído su peculio, o por una tía solterona que no ha querido dejar la casa natal, renunciando ambos a todos sus derechos sucesorios y transmitiéndolos al heredero de la propiedad» ${ }^{15}$. Abel Poitrineau aprecia un desequilibrio significativo en el balance demográfico de la región en beneficio del elemento femenino: el Cantal en el siglo XIX es uno de los polos de soltería femenina ya que el emigrante se caracteriza por «una nupcialidad tardía y poco intensa». En efecto, la conjunción de varios factores conduce al viajero a casarse tardíamente, bien porque, aportando una dote mayor espera pretender a una heredera, bien porque el exilio y la soltería le convienen. De los 202 panaderos auverneses de Madrid (son muchos más) que proporcionan información sobre su estado civil en 1866, he constatado la existencia de 158 solteros, es decir, el $78 \%{ }^{16}$. En suma, creemos que los solteros son a menudo los grandes excluidos, puesto que lo son en varios planos: excluidos del patrimonio y del matrimonio, excluidos de la instrucción y de la consideración general. Están, como dice de manera sugestiva Arlette Farge, "en el ángulo muerto de la historia»" ${ }^{7}$.

\section{Homogamia y exclusión: la casta de los comerciantes rurales}

En las comarcas en donde la emigración hacia España es mayoritaria (Crandelles, Ytrac, Saint Paul des Landes, Teissières de Cornet, Pleaux, Laroquebrou, Sansac de Marmiesse...), la endogamia familiar es reforzada por una fuerte homogamia y la elección del cónyuge pasa por un doble filtro, la paridad patrimonial y la paridad comercial. Así, un propietario de Crandelles, comerciante pañero cerca de Toledo, casará a su hija con un vecino del mismo origen migratotio; el habitante de Mauriac, tahonero en Madrid, hará otro tanto. Puede ocurrir también que los bienes de la heredera de una familia sedentaria encuentren su complemento en el dinero procedente de la emigración, pero

s LAPAdRelie, J.: «Une variété du type auvergnat», La Science Sociale, XXVII, janv. 1899, p. 33.

16 Otras estimaciones en Les Autergnats de Castille, op. cit.

17 Cabe recordar el trabajo precursor de Pierre Bourdieu, "Célibat et condition paysanne», Étuder rurales, $1962, n^{\circ} 5-6$, p. 32-135.

Hipania, LX/1, núm. 204 (2000) 315-330 
generalmente el matrimonio consagra el paso de una casa de emigrantes a otra casa con un nivel de vida equivalente. En una sociedad rural regida por un modelo matrimonial y migratorio tan apremiante, las estrategias de matrimonio y de emigración se entrelazan. La endogamia es una pieza esencial del mecanismo migratorio. Las familias de la emigración se alían entre ellas formando «castas": se apoyan, se avalan, se cooptan, tanto en el medio emisor como en el receptor. Como prueba de esta endogamia, citaré el caso de la Compañía de Chinchón: en 1808, de 96 miembros, encontramos solamente 39 patronímicos diferentes: Laveissière y Conthe en 6 ocasiones, Bac, Vermenouze y Vigier 7, Maisonobe 9, etc. Las relaciones entre ellos son múltiples; por ejemplo, dos hermanas Vermenouze están casadas con dos hermanos Maisonobe ${ }^{18}$... Los matrimonios consanguíneos son numerosos en las regiones donde encontramos comunidades profesionales familiares como consecuencia de acomodos de bienes raíces y comerciales.

\section{Matrimonio mixto y disidencia}

Aunque lo llamen el segundón, restándole importancia ipso facto, el excluido de la propiedad es una fuente de ingresos. Mientras no se case, el padre puede esperar, a cada regreso, una parte de sus ganancias. Si se casa en España, no traerá ni un ochavo más y se alejará de sus compatriotas. «iMal haya quien se case con una española!» se encuentra en ocasiones escrito en los reglamentos de las compañías, pero en general la convención es tácita. Puedo citar a familias españolas de Madrid con patronímico francés, descendientes de excluidos; pienso, por ejemplo, en las cuatro familias Vermenouze cuyo abuelo, Hippolyte Vermenouze, murió en 1876 trabajando en los ferrocarriles españoles, adonde había ido a parar tras su exclusión de una compañía cantalesa por haberse casado con una castellana. Se trata de una aventura irrelevante, pero adquiere toda su importancia cuando se sabe que en la familia española se ha transmitido el recuerdo de una implacable expoliación. Hojeando distraídamente la guía telefónica de Madrid, Pierre Vermenouze, cronista de Crandelles, descubrió a estos primos que habían sido totalmente olvidados por el clan.

Sin embargo, a la larga, estos segundones, sobre todo los más desheredados - stricto sensu-, tenderán a casarse en el extranjero. "Matrimonio por amor, privilegio de pobre»... Esto explicaría ciertos porcentajes impresionantes del Siglo de Oro - período de emigración auvernesa masiva - citados por E. Giralt/J. Nadal (Barcelona) y J. Bravo Lozano (Madrid), quienes evalúan, grosso modo, en un cuarto la proporción de maridos franceses en ciertas parroquias, mientras que el porcentaje disminuye en la época contemporánea, en la que

is Archives Départementales du Cantal, 114; JEAN-MARIE GoutsSE, F.: «Mariage de proches parents (XVIe-XXe siècles). Esquisse d'une conjoncture», Le modele familial europén, op. cit., p. 49. 
esta emigración se vuelve elitista. El emigrante no olvida que corre un peligro socio-económico al desvincularse no sólo de su comunidad de origen, sino también, y como consecuencia, de la estructura comercial montada en el extranjero. La prudencia implica seguridad, y, por ello, la tasa de soltería de los emigrantes se ve reforzada.

\section{¿Quién emigra?}

No se puede comprender quién emigra si no se ha intentado retratar primero el binomio elegido/excluido. Digamos para empezar, que, contrariamente a lo que se podría pensar, todos los hombres de la familia troncal, sin excepción, son susceptibles de irse, tanto el heredero como el excluido. Vayamos por partes:

1. El beredero puede perfectamente expatriarse cuando no deja a su mujer y a sus hijos sin sustento económico. Normalmente, irá a un comercio regido por sus parientes o por su familia política — suegro o cuñado. Se impone entonces una condición: la ganancia debe compensar ampliamente los gastos extraordinarios que su familia debe hacer en sueldos a domésticos, en salarios a jornaleros, para mantener su explotación agrícola en producción durante los años de ausencia. Lo que quiere decir que tal desplazamiento está reservado casi exclusivamente a los comerciantes que disponen en España de un establecimiento lucrativo.

2. El yerno se expatría aún más fácilmente, ya que deja a su esposa en el hogar paterno, donde siguen viviendo viejos y jóvenes susceptibles de echar una mano en las tareas agrícolas. Es el emigrante ideal en caso de que la dote que se aporta no sea suficiente para pagar, o para completar, las legítimas de sus cuñados.

En el caso del yerno, y en el del heredero también, la explotación familiar permanece bajo la tutela de un jefe de familia de más edad, padre o suegro, sedentario o emigrante retirado; pero también, y más a menudo de lo que se piensa, puede permanecer bajo el control exclusivo de la esposa.

3. Los excluidos del patrimonio emigrarán si disponen de medios suficientes para hacerlo. Este tipo de emigración a España es caro. La indemnización a los jóvenes excluidos puede ser precisamente la prima con la que emigrar. En efecto, el dinero de una legítima puede servir como derecho de admisión en una sociedad comercial: algunos, los "ricos", se van con los 4000 francos de fianza exigidos en 1800 para poder entrar en una sociedad comercial tan próspera y selectiva como la de Chinchón; otros, podrán contar solamente con algunas centenas de francos, lo necesario para la compra del caballo y los gastos del viaje; por último, la legítima puede reducirse a un viático que asegure el albergue, la comida y unos zapatos para la marcha de un mes. La emigración a España ya no es a partir del siglo XVIII aquella emigración de gabachos descal- 
zos reflejados en la literatura del Siglo de Oro ${ }^{19}$. Sin embargo, todos los excluidos decimonónicos no son iguales: al marcharse, no tienen las mismas posibilidades de triunfar; y en España, la célula comercial auvernesa, muy pragmática, asociará emigrantes explotadores y emigrantes explotados.

Lo lógico es que el desheredado quiera, a la vuelta de los años, entrar como yerno en una familia troncal, siendo el dinero en metálico el mejor argumento para unos buenos «esponsales». Pero aquellos cuyo hotizonte socio-cultural es aún más limitado parecen propensos a la soltería definitiva. Los encontramos a veces en los registros de algún hospicio (pienso en el hospital Saint-Louis-desFrançais de Madrid).

\section{¿X las mujeres?}

Las mujeres no emigran a España. Con la apertura de la línea férrea IrúnMadrid en 1866, algunas pioneras harán su entrada en escena, pero su número no es significativo, y los reglamentos de las sociedades mercantiles las ignoran o las excluyen muy explícitamente. En algunos contratos se puede leer: «Sólo podrán venir de visita y nunca dos al mismo tiempo».

Poco he hablado de las mujeres hasta ahora; todo lo más he señalado como líneas generales el contingente de hijas solteras que se quedan en la familia, se colocan en las granjas, en el pueblo, entran en el convento o se convierten en simples menettes ("señoritas devotas»), una especie de monjas laicas vinculadas al servicio de una parroquia, de una congregación, de un pensionado, o simplemente de una familia. Es muy digno de interés universitario este celibato que viene inducido por una estrategia matrimonial excluyente y por una emigración a larga distancia, pero aquí, sin embargo, me detendré en la figura de la heredera porque ella es quien imprime originalidad al «sistema de casas» del Cantal.

Cuando examinamos las razones esgrimidas por generaciones de emigrantes cantaleses para impulsar las salidas y, al mismo tiempo, para paliar las ausencias (toda la ambigüedad está ahî), nos damos cuenta de que la institución más «estructurante» es la de una heredera. Que una hija sea «la elegida patrimonial" no tiene nada de extraordinario; lo que es sorprendente dentro del grupo social observado es el alto porcentaje de herederas, ya se trate de la mayor o no, ya tenga hermanos o no. Según mis estimaciones, la hija es «convertida en la mayor" una de cada dos veces (aunque cabe preguntarse por la fiabilidad de la muestra estudiada). He aqui dos sondeos:

19 En el siglo XVIII, las legítimas para las hijas son más importantes que para los hijos. La ex+ plicación que dan los padres es la siguiente: «[Pierre Carles declara] restringir a cada uno de sus hijos a la suma de 200 libras por todo derecho en sus bienes, sabiendo que ya ha hecho gastos para enviar a los dos primeros a comerciar fuera del reino, y que se propone enviar igualmente a los orros", 21 de junio de 1770, Trasssac, E.: op. cit., p. 243. El verbo emiar (el subrayado es mío) parece no admitir téplica: adivinamos que el emigrante no tiene elección y que la heredera será una chica. 
1. Según la reconstitución familiar de Paul Roquetanière y Pierre Vermemouze, que abarca los siglos XVIII y XIX, de 58 parejas de emigrantes comprobadas (no es fácil detectarlas), se cuentan 28 herederas y 30 herederos.

2. Según la reconstitución de Elisabeth Traissac, se suceden en la «Casa de Malbert", en el siglo XVIII, Hélis Parieu, Anne Lavernhe, Hélis Cas, Pierre Carles y Anne Carles, es decir, 4 herederas en 5 generaciones ${ }^{20}$, etc. Prefieren conservar a la hija en casa y mandar a los hijos a emigrar, estudiar, servir, etc. Así, el jefe de familia conserva más fácilmente y durante más tiempo la práctica del poder. Pero, ino es la heredera la verdadera beneficiaria de esta estrategia, quedándose por más tiempo en la estructura familiar, hasta que, llegada la hora, toma las riendas del poder? Se ha demostrado que el matrimonio con residencia uxorilocal protege mejor los derechos de la mujer. El privilegio para ellas es indiscutible, y en este sentido se puede hablar de una semi-exclusión de los hombres, sobre todo si se compara con lo que pasa en la mayoría de las zonas de transmisión íntegra.

La tarea de las mujeres es compleja cuando los «viejos» han desaparecido (a menudo muy pronto) y los hombres están lejos: «¿Cómo se aprovechan las mujeres de esos poderes y de esas fallas, de esas porciones que les dejan, de esas misiones que les confían?» ${ }^{21}$. Para ellas, la emigración supone, sin duda, una oportunidad para imponer sus opiniones acerca de la regulación y prevención de los desequilibrios ya que, al ser curadoras (con poderes especiales o generales), disponen de un gran margen de maniobra y tienen autoridad para decidir «lo más conveniente» en la mayoría de los casos. El único derecho que se les niega en el siglo XIX es el de casar a los hijos; para cada enlace, la licencia será enviada desde el consulado por el marido, lo que demuestra que el matrimonio es el «asunto", «la grande affaire».

De forma interina, pues, les incumbe la tarea de dirigir la explotación. Es indudable que la sempiterna cesión de poder a la mujer permitió a más de un marido viajero esquivar la responsabilidad de la dirección.

\section{«iVae victis!» iAy de los vencidos!}

En este verdadero turn over del poder originado por la emigración, ellas aseguran la continuidad y la supervivencia de la explotación ${ }^{22}$. El ineludible cometido del emigrante es en cambio traer dinero.

20 Duroux, R: «Femme seule, femme paysanne, femme de migrant», Le paysan, lle colloque d'Aurillac, París, Ed. Christian, 1988, p. 147-178.

${ }^{21}$ Colectivo, «L'Histoire des fernmes. Culture et pouvoir des femmes. Essai d'historiographie», Annales ESC, marzo-abril $1986, \mathrm{n}^{\circ} 2$, p. $285-286$.

22 Las «procuraciones», firmadas ante notario en Auvernia o ante el cónsul en Madrid, no dejan lugar a dudas al respecto. Cuando, además, se tiene la suerte de dar con la correspondencia 
Pese a las estrategias, más de una vez, la familia troncal tropieza con el agravamiento de un endeudamiento crónico (el cual, como se sabe, no significa pobreza). A las deudas estructurales (tales como las legítimas que hay que pagar) vienen a añadirse las coyunturales, cuyos pagos deben realizarse necesariamente tras la vuelta de los emigrantes provistos de dinero en metálico. Más allá de cierto grado de endeudamiento, se instauran situaciones de crisis en función de la capacidad o incapacidad física, moral o económica del matrimonio: «Más de un yerno o de un marido, constatando el mal estado de los negocios de la casa de su mujer, aterrorizado por las deudas, decide escaparse a España» ${ }^{23}$. El fracaso de las campañas migratorias, en una sociedad que las ha afinado para asentar el patrimonio territorial, evidencia el fracaso de las estrategias del grupo doméstico; fracaso intolerable que precipita el rechazo del emigrante descalificado, forma drástica de exclusión o de auto-exclusión.

\section{Patrimonio y madre patria}

Imaginamos lo diversas y ambiguas que son las razones de la emigración definitiva. Me detendré en una que ya ha dado mucho que hablar, me refiero al servicio militar, el cual, en esas tierras altas, es frecuentemente evitado por los mozos o por los casados sin hijos, expatriándose ${ }^{24}$. He podido comprobar que en el Cantal los emigrantes por esta razón exan muy numerosos, al menos antes de la Primera Guerra Mundial ${ }^{25}$. En su Ensayo sobre la estadística de la población francesa de 1836, A. d'Angeville clasifica el Cantal en el primer lugar por la cantidad de estos rebeldes y afirma: «Por 1000 reclutados obtenidos, se cuen$\tan 130$ tebeldes; el departamento promedio tiene 14. Ningún departamento cuenta con más insumisos» (subrayado por Angeville). En este sentido, los «Se-

\footnotetext{
conyugal, se está en condiciones de apreciar las reticencias de los maridos así como sus abdicaciones, confesadas o no.

23 PoITRINeAU, Abel: Les «Espagnols» de l Auvergne et du Limousin du XVIIe au XIXe siècle, Aurjllac, Mazel-Malroux, 1985, p. 127.

24 Esquer, Gabriel: aLa Haute-Auvergne à la fin de l'Ancien Régime», Revue de la HauteAuvergne, 1910, p. 233. Comentario del recaudador del vingtième en 1788: "Ahora que se verifica el sorteo del 15 de julio al 15 de agosto, sólo vuelven al país jóvenes cuya talla es inferior a cinco pies. Los hombres guapos se quedan en España, donde se establecen. Todo lo pequeño y mal hecho se casa aquí; las tres cuartas partes de las jóvenes no encuentran con quién casarse; nuevo zipo de despoblación. Podemos predecir que dentro de cincuenta años la población de nuestras montañas será una raza de pigmeos o de lapones».

25 Duroux, $\mathbf{R}$ : «De l'insoumission à l'émigration, ou l'inverse?», Las migraciones internas y de medium-distance en la Peninsula Iberica, 1500-1900, $\mathrm{I}^{2}$ Conferencia Europea de la Comisión Internacional de Demografía Histórica, Universidad de Santiago de Compostela, 22-25 de septiembre de 1993, Ed. Ofelia Rey Castelao y Antonio Eiras Roel, 1994, t. 1, p. 469-487. Se pueden citar casos precisos en que la familia troncal es la que incita al segundón a la insurnisión/expatriación. Véase $A$. d'Angeville, infra, París-La Haye, Ed. Mouton, 1969, p. 192.
} 
ñores de Chinchón» - -así es como se designa a los miembros de la rica compañía mercantil susodicha- se harán costear en Aurillac (capital de la provincia) «exenciones en metálico»; los que no tienen este recurso esperarán la amnistía o simplemente ya no volverán.

Consultando estadísticas y testimonios se adquiere la convicción de que la insumisión bien pudo entrar en las estrategias de la familia troncal cantalesa. Dicho de otro modo: los refractarios a la quinta continuarán asegurando con su actitud la continuidad del comercio familiar más allá de los Pirineos $\mathrm{y}$, por lo tanto, seguirán trabajando para la «casa». No puede sorprendernos entonces el hecho de que las comarcas cantalesas con una gran emigración hayan sido las más rebeldes, como tampoco ha de extrañarnos que la insumisión sea, mayoritariamente, el destino elegido por los segundones sin tierra.

\section{CONCLUSIÓN}

Hemos intentado comprender los mecanismos de protección que han ido elaborando los habitantes del Cantal, una región en la que predomina la pequeña explotación agrícola, para paliar las disfunciones nacidas de una emigración temporal, la cual se articula a su vez sobre un soporte mayor, «el sistema de casas" : un sistema sucesorio conflictivo pero eficiente. Esto nos ha permitido aportar una visión transversal a este dispositivo central.

El siglo XIX no ha inventado este sistema y como en los siglos pasados -un pasado que podríamos remontar hasta el siglo XV-, las migraciones siguen yendo parejas al sistema sucesorio. Los grupos domésticos apenas han maquillado las irregularidades que origina la exclusión para adaptarlas al derecho contemporáneo. Llegamos así a la convicción de que la emigración a España no es una ruptura sino más bien un refuerzo al orden social establecido; proporciona un cómodo margen de maniobra; es una válvula de escape para los campesinos. Por este motivo, economistas del siglo pasado como F. Le Play aplauden esta "emigración rica", nacida de familias troncales, que hay que alentar, y deploran en cambio la «emigración pobre», resultado desafortunado de la familia inestable. Hemos visto que el mecanismo de la familia troncal, a pesar de la convergencia de esfuerzos, a pesar del omnium consensus, no siempre funciona correctamente. El desmembramiento patrimonial, por mucho que lo contrarresten las prácticas sociales, termina por introducirse, por ganar terreno, tal y como lo revela el catastro parcelario. Esto no impide que el principio sea mantenido a contracorriente de la historia, hasta que tenga lugar, como hoy, la «deserción de los 'herederos' en las tierras altas». 